\title{
Cash Flow System Development Framework within Integrated Project Delivery (IPD) using BIM tools
}

Faris Elghaish ${ }^{\mathrm{a}^{*}}$, Sepehr Abrishami ${ }^{\text {a }}$, Soliman Abu Samra ${ }^{\mathrm{b}}$, Mark Gaterell ${ }^{\mathrm{a}}, \mathrm{M}$. Reza Hosseinic ${ }^{\mathrm{c}}$ Richard Wise ${ }^{\mathrm{a}}$

aSchool of Civil Engineering and Surveying, Portsmouth University, Portsmouth, Hampshire, UK, PO1 2UP; ${ }^{b}$ Dept. of Building, Civil and Environmental Engineering, Concordia Univ., Montreal, QC, Canada $\mathrm{H}_{3} \mathrm{G}$ 1M8; 'School of Architecture and Building, Geelong Waterfront Campus, Deakin University, Locked Bag 20001, Geelong VIC 3220, Australia.

*faris.elghaish@port.ac.uk PhD. Researcher at School of Civil Engineering and Surveying, Portsmouth University, Portland Building, Portland Street, Portsmouth PO1 3AH UK . Telephone: +44 (0)2392842903 


\section{Cash Flow System Development Framework within Integrated Project Delivery (IPD) using BIM tools}

Integrated Project Delivery (IPD) endeavour to revamp AEC project outcomes through a collaborative method of regulating project stakeholders' goals through creation of a platform that provide early participants involvement and shared risk and rewards. IPD does not include a tender stage to select the optimal bid, therefore, this paper presents a methodology framework to develop a cash flow approach using BIM tools. This paper adopts Activity Based Costing $(\mathrm{ABC})$, due to its ability to allocate different costs precisely to each construction process. Given that the BIM and IPD target is to achieve the best collaboration among project parties, the proposed framework backing this by displaying all estimated cost data of each package as minimum/maximum estimated cash inflow, during the buyout stage, for informed decision making. This paper extends the knowledge relating to IPD implementing process, as well as, improving cost management process based on BIM. Extant literature review highlights the gap of utilising BIM tools to develop cash flow curves, as well as the IPD cost structure requirements. To demonstrate the applicability and validity of the proposed model, it is applied to a real-life case study, which displays promising results in terms of developing IPD's cash flow management approach.

Keywords: Cash flow; Cash inflow/outflow; BIM; Integrated Project Delivery (IPD); 4D/5D BIM; Activity Based Costing (ABC). 


\section{Introduction}

Cui et al. (2010) asserts that the mismanagement of cash flow in construction projects leads to several issues in implementing construction projects properly. The cash flow overdraft is caused due to the lack of cash flow management since the estimated expenses are less than the actual required (Kishore et al., 2011). Elazouni (2009) states that the integration of cost and schedule is required to draw the cash out curve ( $\mathrm{S}$ curve). However, the integration of cost/schedule is not effectively implemented (Lee et al., 2011). The traditional integration of cost and schedule is time consuming and causes a significant waste of information (Kaka, 1996; Kim and Grobler, 2013). Kim and Grobler (2013) state that utilising Building Information Modelling (BIM) can improve the traditional cost/scheduling processes. Lu, Won and Cheng (2016) state that there have been several studies for analysing cash flow processes, however, most of research does not consider the differences between project delivery approaches. Since each delivery approach has distinguished relationship between project parties, therefore, the management of cash out should be compatible with the delivery approach.

Batselier and Vanhoucke (2017) exploited the EVM metrics along with the exponential smoothing forecasting approach to articulate a systematic model to predict project costs and durations. Moreover, Andalib, Hoseini and Gatmiri (2018) developed a model to predict the owner's financial behaviour during the project execution, using the previous financial records. Even though, the developed model gives a forecasting index with respect to the risk perception to similar projects, but generally were designed to predict the cash inflow, regardless of delivery approach used. Furthermore, Carbonara and Pellegrino (2018) developed a methodology to determine the optimal values of the revenue floor, as well as, revenue ceiling. This methodology was designed particularly for Public-Private Partnership (PPP) and there are two caps either to share risks or revenue; these are the revenue floor to ensure the minimum 
'The Version of Record of this manuscript has been published and is available in international Journal of Construction Management (TJCM), Jan 2019, http://www.tandfonline.com/10.1080/15623599.2019.1573477 '

revenue for contractor, and the revenue ceiling, which defines maximum profit can be achieved by the contractor, and any amount of revenue after the revenue ceiling will be shared. Even though this payment is partly similar to the IPD structure, however it is missing a crucial limb, which is the cost saving sharing. Moreover, the contractor in IPD could yield to zero revenue in case that the cost/schedule performance is poor.

Lu, Won and Cheng (2016) developed a methodology framework to analyse cash flow, which consists of cash in and cash out. The developed model exploited the 5D BIM capabilities to determine the precise costs of resources for reliable cash outflow ( $\mathrm{Lu}$, Won and Cheng, 2016). The model used BIM tools for developing the cash flow curves, however, this study did not consider specific delivery approach for BIM projects. Ilozor and Kelly (2011) suggested that the integration of BIM and IPD can enhance the entire outcomes of design and construction process since this integration is associated with several parameters such as; cost/profit, schedule, safety, productivity and relationships. Lu, Won and Cheng (2016) developed a cash flow methodology that proposed detailed models for material, equipment and labour cash outflow using 5D BIM capabilities, however the delivery approach characteristics have not been considered (i.e. profit at risk sharing percentage for IPD approach).

Extensive literature review is used to explore state of the art BIM tools and capabilities regarding schedule (4D BIM) and cost (5D BIM). Several methods reported in the literature for using BIM to develop reliable cash flows methodologies, and IPD's cost structure approach to successful BIM projects delivery. For the validation and applicability of the proposed framework, a real-life case study is conducted. Since IPD depends on sharing risk/rewards between project parties, this requires tailored cash flow curves for this kind of payment. The sharing risk/rewards system relies on agreed profit at risk percentages at buyout stage, thereby, the forecasted cash inflow will be proportional values, not exact numerical values as traditional delivery approaches. The proposed framework includes different scenarios for cash flow curves 
'The Version of Record of this manuscript has been published and is available in international Journal of Construction Management (TJCM), Jan 2019, http://www.tandfonline.com/10.1080/15623599.2019.1573477 '

(cash inflow/cash outflow) to support decision making at buyout stage by exposing all possible cash flows to all parties before construction stage and accordingly maintain a trust worthy collaboration environment during the construction stage. Furthermore, this research addresses the inherent problem of schedule/cost integration due to the inconsistency between Cost Breakdown Structure (CBS) and Work Breakdown Structure (WBS) by exploiting the Activity Based Costing $(\mathrm{ABC})$ to estimate project costs, as well as the project schedule breakdown by following ABC hierarchy. Love et al. (2011) reported that the cost structure, which comprises direct, indirect, and overhead costs, must be considered in the compensation structure approach, since the risk/rewards proportions rely on the degree of the achievement during the entire project stages. Therefore, $\mathrm{ABC}$ prevents this distortion by allocating the costs through multi-pools, and determines the overhead activities and costs needed to transform the resources into activities that can deliver the final product (Kim and Ballard, 2001). In order to address the issues outlined above, this research proposes the integration of cost and schedule into the optimised cost structure of IPD regarding direct, indirect and overhead costs, which is implemented through $\mathrm{ABC}$.

The structure of this papers will be literature review, methodology and framework development sections. Regarding the validation of the proposed framework, a real-life case study will be conducted, and the case study results will be analysed. Finally, the conclusion will follow to highlight the research findings as well as the future research and limitations.

\section{Literature Review}

\section{BIM and cash flow}

Interdependencies between the cost (BIM 5D) and schedule (BIM 4D) are obvious due to the integration between cost and schedule processes, in a single system, which is necessary to establish appropriate control. However, in practice, the two parameters are still separate, given that the schedule is represented by Work Breakdown Structure (WBS), whilst the costs are 
'The Version of Record of this manuscript has been published and is available in international Journal of Construction Management (TJCM), Jan 2019, http://www.tandfonline.com/10.1080/15623599.2019.1573477 '

identified by Cost Breakdown Structure (CBS) (Fan et al., 2015). Hence, during the budgeting stage, the integration between the WBS and CBS becomes complex, thus, leading to potential errors and mismatch (Jung and Woo, 2004).

According to Fan et al. (2015), the initial steps to integrate BIM 4D and 5D are creation of the project schedule and BIM models, and cost estimation of all design elements. Subsequently, the generated cost items need to be linked with the project schedule (BIM 4D), and BIM element linked to the schedule. However, this process has some shortcomings when it comes to implementation, particularly linking the BIM schedule to the generated cost. Therefore, the BIM elements should be linked directly to the cost items to avoid the complicated process of integrating these elements with the schedule (Fan et al., 2015).

Kim (1989) developed a costing system model to manage cost estimation, budgeting and control, however, the proposed model (basic construction operation), which indicates the lowest level in construction operation that has linked to three sources, namely; WBS, CBS, and design files (Kim, 1989). This system has been criticised by Rasdorf and Abudayyeh (1991) due to it requires a high level of details, as well as, refining each operation in order to reach sub-task, which is not practical and applicable in AEC industry (Rasdorf and Abudayyeh, 1991).

Since the classification of construction works is vital to reliable budget, Kang and Paulson (1998) developed a classification system based on four categories, namely; facilities, Spaces, elements and operations. Subsequently, the cost and schedule is considered for each level in each category for a construction project, however, the proposed classification system is not suitable for quantity take-off in cost estimation process (Wang et al., 2016). Given this, the challenge of detailed cost estimation with consistent WBS hierarchy remains persist in AEC industry, particularly when using the work-packaging (WP) method, which relies on the cost/schedule control system criteria (C/SCSC) in the package level. However, this is not 
'The Version of Record of this manuscript has been published and is available in international Journal of Construction Management (TJCM), Jan 2019, http://www.tandfonline.com/10.1080/15623599.2019.1573477 '

efficient, due to the construction operations involves long hierarchy levels to reach sub-task level (Moder, 1983). Even though the method assigns the cost to WBS regardless of CBS, nonetheless, Rasdorf and Abudayyeh (1991) assert that it needs some improvements to make it applicable in complex projects.

Yang et al. (2007) developed a model to integrate the budget (override the resources) directly to the schedule, in daily proportion, to develop BCWS, and each activity will be weighted daily as ratio relative to the schedule, and this ratio will be used to measure the progress (Yang et al., 2007), notwithstanding daily scale in construction projects may be impractical (Wang et al., 2016). Chou et al. (2013) developed a model which is entitled a 5W1H (what, when, where, who, why and how) in order to solve the challenge of integrating cost/schedule in construction project. So that, the planner can follow the operation as multi-function within multi-level such as the what (would be a column), how (framework), and answers of other questions, in order to give more details to enable the integration (Wang et al., 2016).

According to Eastman et al. (2011), there is not a full functional BIM cost management software, therefore the quantity surveyor should link between different platforms in order to carry out the main three tasks, namely: estimation, budget, and control. Even though, Lawrence et al. (2014) developed a model to update the estimated cost automatically based on design changes, withal the entire estimation will be unreliable due to lacking plenty of information, which is not embedded in the design. Moreover, Wang et al. (2016) developed a model to integrate cost/schedule based BIM. The developed model links between the BIM design object, cost item, activity, and area (zone/floor). Even though, the proposed model used BIM in formulating project budget, yet the process does not support the automation.

\section{The correlation of IPD and Building Information Management (BIM)}

The American Institute of Architects [AIA] (2007) defines IPD as "a project delivery approach that integrates people, systems, business structures, and practices into a process that 
'The Version of Record of this manuscript has been published and is available in international Journal of Construction Management (TJCM), Jan 2019, http://www.tandfonline.com/10.1080/15623599.2019.1573477'

collaboratively harnesses the talents and insights of all project participants to optimize project results, increase value to the owner, reduce waste, and maximize efficiency through all phases of design, fabrication, and construction” (AIA, 2007). Kent and Becerik-Gerber (2010) states that there are some criteria, which distinguished using IPD in BIM projects namely; multiparty agreement, early involvement of all parties, and shared risk and reward. Furthermore, Bedrick and Rinella (2006) asserts that BIM has enhanced the efficiency of construction process by improving the collaboration among a wide range of project participants, through different stages, whether design or construction. On this basis, the comprehensive decision making must be considered at the early design stage (Ashcraft, 2008). Subsequently, DeBernard (2008) argued that implementing IPD can optimise the delivery timeline of construction projects by reducing waste within better planning and shared risk/rewards. Therefore, the optimisation of 4D BIM can play a vital role in reducing cost and enhancing the entire efficiency for construction process. Montaser and Moselhi (2015) noted that 4D BIM is dynamic presentation for the design by considering the time parameter, which leads to easier understanding rather than traditional method.

\section{Activity Based Costing and Indirect Costs}

As a result of the fragmentation in construction projects, and the types of project, participants must vary, which leads to an increase in the overhead activities and hence, the overhead costs will rise (Kim and Ballard, 2001). The traditional cost accountant method is called Resource Based Costing (RBC), which relies on the cost of the resources (Kim and Ballard 2001, Holland and Hobson 1999), in which Cost distortion occurs when using the traditional methods of costing, because these allocate all indirect and overhead costs proportionally, could distorts the pricing for the company's products (Miller 1996). ABC prevents this distortion by allocating the costs through multi-pools and determines the overhead activities and costs needed to 
'The Version of Record of this manuscript has been published and is available in international Journal of Construction Management (TJCM), Jan 2019, http://www.tandfonline.com/10.1080/15623599.2019.1573477 '

transform the resources into activities that can deliver the final product (Kim and Ballard, 2001).

Chiang (2013) defines the overhead cost as ongoing costs of a business that contribute to the whole process rather than specific cost object. According to Markarand Hastak (2015), direct cost are those resources which are consumed to accomplish activity, and these resources will shape cost object by performing some activities. The activity hierarchy levels in the organisation refers the nature of the relationships between the activities of the organisation so as to achieve sustainability of the information throughout the project and/or the organisation levels (Kim and Kim, 2016). Wang et al. (2010) assert that the traditional costing system, which uses a single cost deriver such as direct cost proportion of each package or its volume relative to the entire product in order to allocate the overhead cost, which cause cost estimation distortion, could leads to poor decision due to the final price of the product being unreliable and in most cases, this affect the organisation competitive opportunity (Wang et al. 2010).

Regarding the pricing process, $\mathrm{ABC}$ provides a meaningful analysis method to measure all costs, whether financial as driver rates, or non-financial as transaction volume. On this basis, the pricing process will be more accurate, enables articulating a proper budget, and enhance the controlling system (Dandago and Tijjani, 2005). Accordingly, any activities without specific process or design elements should be minimised or eliminated in order to enhance the entire construction process (Clark et al., 2002). Furthermore, Tsai et al. (2014) developed a model for Life Cycle Assessment (LCA) using ABC, due to its ability to identify the construction process activities of a project life cycle, and, the cost estimate is prepared for each activity individually. The capability of $\mathrm{ABC}$ in cost estimation/analysis, as well as $\mathrm{ABC}$ ability to enable user to track all project costs, is conducted by Fang and $\mathrm{Ng}$ (2011).

\section{Cost structure of Integrated Project Delivery profile}


'The Version of Record of this manuscript has been published and is available in international Journal of Construction Management (TJCM), Jan 2019, http://www.tandfonline.com/10.1080/15623599.2019.1573477 '

According to Ashcraft (2009), the most important character of using the IPD approach is the compensation system to allocate the gain/pain ratios between project participants. The IPD approach needs a cooperative contracting relationship, which leads to motivate core team members to achieve project objectives. Therefore, multi-agreements should be agreed with all participants in order to determine the suitable compensation percentage to undertake the project. According to Thomsen et al. (2009), the compensation approach structure must specify the methods which will be used to determine the proportions of Cost Overrun; Cost Underrun; and any other saving in the total budget under the agreed cost. Moreover, Love et al. (2011) reported the cost structure (which comprises from direct, indirect, and overhead costs) must be considered in the compensation structure approach due to the risk/rewards proportions rely on the degree of the achievement during the entire project stages. According to El Asmar et al. (2013), the IPD is more suitable with using BIM rather than project alliancing approach due to IPD procurement approach has the model which enables involvement of all project participants from the conceptualisation stage and consider the compensation approach from this early stage, in accordance with the liable participants.

According to Das \& Teng (2001), the precise determination of risk perception is critical to ensure that the agreed compensation structure will be implemented properly through the entire project stages. Therefore, the risk/rewards ratios can be allocated fairly between the project participants, so that the participants who carry more uncertain works can compromise this with its profit at risk percentage. However, Delerue \& Simon, (2009) reported that the alliancing agreement can reduce the risk within sharing the information through the entire project stages, due to the succession in risk management process normally depends on the data availability, and subsequently, IPD enables this data through gathering all project participants from an early stage. Furthermore, Ross (2003) states that IPD three lambs can be concluded as Limb 1 which represents the reimbursement of project costs, in which the estimation of project costs must be 
scrutinised by using an open book pricing scheme. This limb must include all costs, which are expected to be incurred during the project implementation stages. Limb 2 which represents the overhead costs for all participants and the profit at risk percentage, whereas, Limb 3 is the profit at risk ratios, as well as, the cost saving.

The literature review revealed that IPD integrated into BIM is the optimal approach to deliver construction projects due to IPD's abilities to maximise the value using risk/rewards sharing system. In the meanwhile, BIM tools can offer all the required technologies throughout the IPD stages. Moreover, previous research shows implementing BIM to articulate cash flow management is feasible, however, the $4 \mathrm{D} / 5 \mathrm{D}$ integration requires a clear methodology to ensure all information will be exploited and presented in the project budget. Considering the IPD cost structure, previous research highlighted the shortcomings of existing cash flow system with regards to IPD, as the project parties need a cash flow system that shows the minimum/maximum cash inflow, and indicating all cost structure (direct, indirect and overhead costs) individually. Therefore, the $\mathrm{ABC}$ has been explored to measure its ability to optimise the cost structure, rather than the currently used RBC method, and the analysis refers to its validity to perform the IPD cost estimation process.

With all above in mind, the literature review showed the necessity of developing a methodology framework to develop a cash flow management system for IPD exploiting BIM technologies.

\section{Methodology}

The research utilised a mixed research method for implementation. Bryman (2001) describes the mixed research method as "a multi-research method for investigating a wide range of complicated data with complex research design for understanding and analysing the research contents". Several techniques were adopted based on the best practices identified in the literature. The conceptual framework was developed after identifying the knowledge gap from the previous scholars and accordingly, fill in the missing gaps (Coughlan et al. 2007). In 
addition, the analysis of literature review leads to articulate an integrated context, which represents different ideas in a single context that shows the contradiction between the theories to build an effective argument [(Baumeister \& Leary, 1997; Bem, 1995; Cooper, 2003)]. Figure 1 illustrates the process of identifying the knowledge gap regarding the inconsistency of traditional cost estimation within IPD. Moreover, it shows the relationship between BIM and IPD for successful project delivery and the criteria for choosing the best costing method such as $\mathrm{ABC}$ to be consistent with IPD's cost structure and develop reliable estimated cash flows for all project parties. Thenceforth, the case study is used to validate the framework and ascertain its degree of applicability and validity through applying all proposed steps to the case study, and subsequently, analysing the findings to highlight whether the proposed framework is valid or invalid. According to Zellmer-Bruhn, Caligiuri and Thomas (2016), experiments are particularly effective in revealing whether the real data can support or refute any proposed procedure, and they can demonstrate the match, if any, between data and a proposed theory. The mixed research method used for this research could be displayed in Figure 1. 


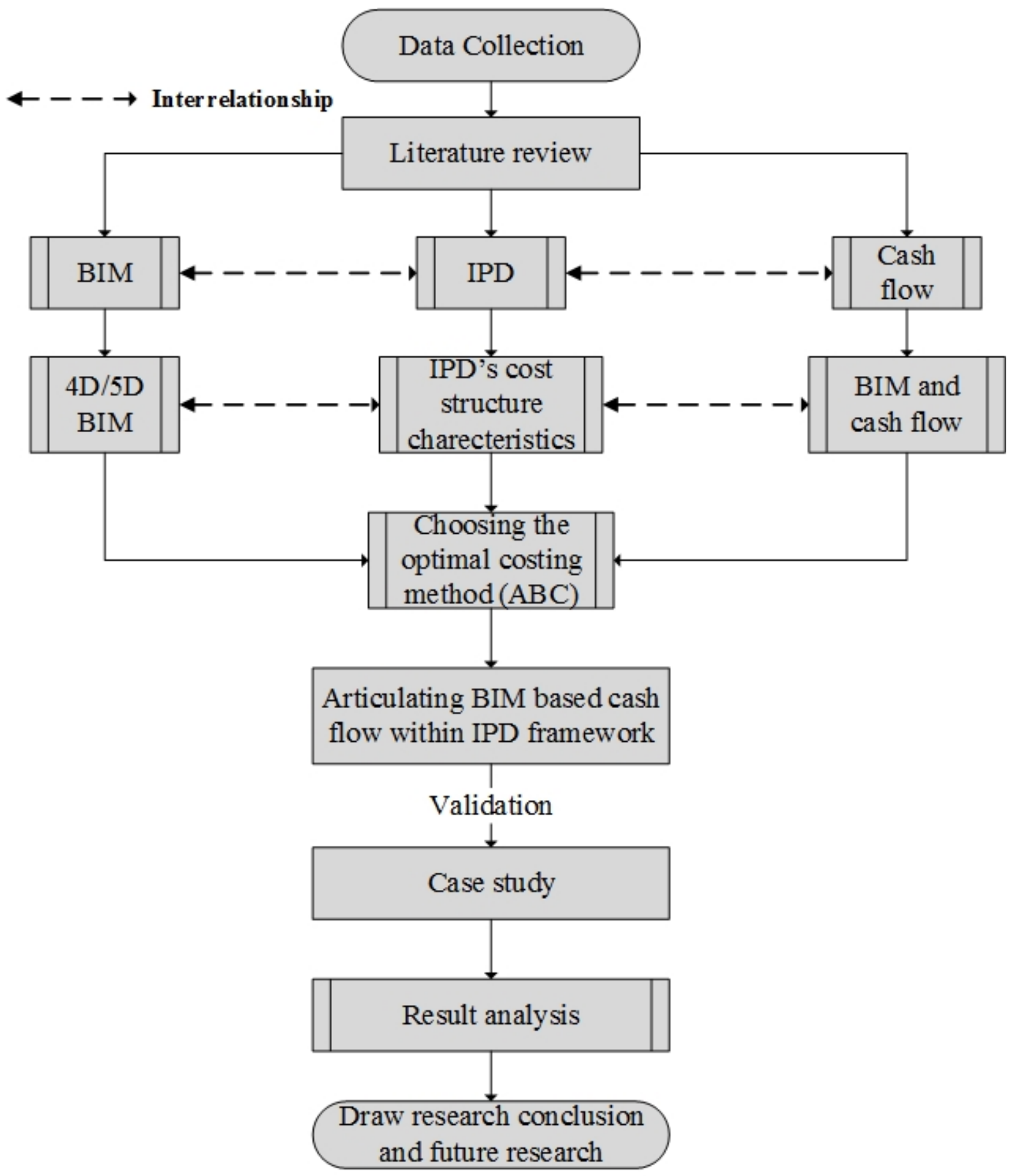

Figure 1. Research Methodology 
'The Version of Record of this manuscript has been published and is available in international Journal of Construction Management (TJCM), Jan 2019, http://www.tandfonline.com/10.1080/15623599.2019.1573477 '

\section{Framework Development}

\section{Integration of data}

This part of the research focus on integrating 4D BIM into 5D BIM to prepare the budget of the project, namely S curve or cash out. This research adopts a new philosophy to manage the relationship between WBS and CBS, since most of recent researches highlights the lack of integration and homogeneity between hierarchy of activities and assembled costs as the main barrier of acquiring a reliable cash out. The cash out is defined as Budgeted Cost of Work Scheduled (BCWS). Since this research adopts ABC to perform the entire cost management process, therefore BCWS includes all project costs (direct, indirect and overhead cost) which will reflect a high level of accuracy due to enabling project participants to monitor all planned and expanded costs. Since ABC relies on allocating the costs from resources to activities, the project costs are already assigned to WBS, and this will solve the highlighted gap in the literature review regarding the fragmentation between WBS and CBS, which causes wastes in cost data and gives unreliable indicators during the construction stage. Given that, IPD approach has five stages before commencing construction, in which two of these stages are to prepare the documentations and forward to buyout stage to reach their consent regarding expected cash flow (cash in and cash out). Therefore, this part of the research focuses on documentation and buyout stage to formulate the model and create a reliable cash flow that is consistent with IPD requirements.

Within this research proposed framework, throughout the documentation stage, 4D BIM is built based on the proposed method highlighted in the methodology section, such that the list of activities should include all types of activities, whether direct, indirect, and overhead activities in order to enable assigning all cost of resources to all activities, without losing any data. In other words, when all activities absorb all resources, the prepared cash out will work effectively, whether during buyout stage to enable participants to take right decision regarding 
accepting or rejecting the offer, or during construction stage, to enable efficient and successful cost control, particularly in IPD, given that the payment depends on the rate of achievement against planned cost and schedule. The quantity surveyor/project manager is responsible to prepare a separate cash out (S Curve) to each participant at this stage to move to the buyout stage and prepare the cash flow for each party, after agreeing on the contractual payment clauses (i.e. risk/rewards sharing percentage, cost control milestones, etc.). Figure 2 displays the steps of implementing framework at this stage. Regarding the buyout stage, IPD approach does not have a tender stage like other approaches, and subsequently all project parties are equally responsible for tender price and the buyout stage, which is an ongoing negotiation until an agreement is reached among all participants. Given that, the buyout stage should be started by preparing critical factors regarding payments, such as risk/rewards percentage, namely; rewards percentage for owner whether cost saving in overhead levels or direct cost level, the rewards percentage for each non-owner parties, and the risk sharing percentage for each owner/non-owner parties. Moreover, the project milestones should be designed for payment purposes, so that each party can predict the sequence of cash inflow during the construction stage, however the costs will be only reimbursed, and profit/risks will be shared after all works will be completed. After accomplishing the payment clauses, the quantity surveyor should start preparing the cash-flow curves for each participant. In the proposed framework, the cash-in is linked to proportional equations, not exact values as traditional approaches. Thereafter, the core team members should hold a meeting to display proposed cash flows to all participants, and ongoing negotiation will take a place to get the consent from each party to begin the construction stage, based on proposed cash flow. In case of some participants reject the offer, it means the owner in cooperation with architect should attempt to find another party to perform the remaining works, without contractor or trade contractors. Agreed participants move to 
construction stage and the agreed cash flows will be added to the contract documents. The proportional models to prepare cash-flow is presented in the next section.

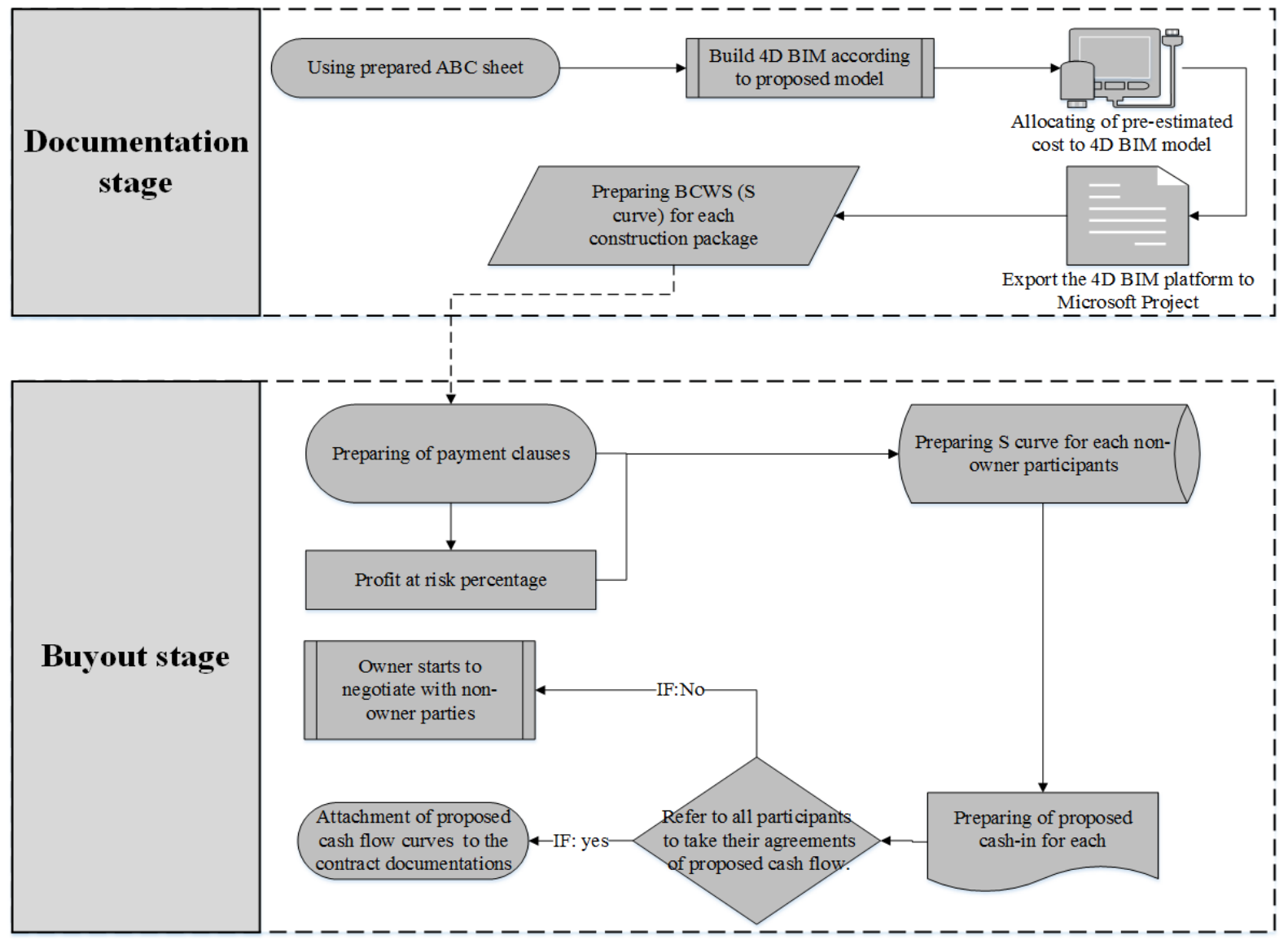

Figure 2. Data Flow within IPD Approach

\section{Formulation cost estimation/budgeting within IPD using ABC method:}

Formulation of the IPD based ABC model:

$$
L I M B 1_{i j}=\sum_{i=1}^{n}\left(\operatorname{CoD} A_{K j}+\operatorname{CoI} A_{K j}\right)
$$

Where LIMB $1_{i j}$ represents the direct and indirect cost for trade contractor $I$, in order to perform trade package $j$; $\mathrm{CoDA}_{\mathrm{Kj}}$ represents Cost of Direct Activity for design element $K$ and trade package $J$; CoIA $\mathrm{Kj}_{\mathrm{j}}$ represents Cost of Indirect Activity for design element $K$ and trade package $J$. 


$$
L I M B 2_{O A}=\sum_{i=1}^{n}\left(N O A_{O A} \times M V O C D_{D A}\right)
$$

Where LIMB $2_{i j}$ represents the overhead costs for specific operation $O$, such as cost control in order to perform overhead activity $A$; NOAOA represents summation number of operations $O$ to perform overhead activity $A$; MVOCDDA represents Monetary Value of Cost Driver $D$ to perform overhead activity $A$.

$$
L I M B 3_{i j}=\sum_{i=1}^{n}\left(L M B 2 \& 3_{i j}\right) \times P @ R \%_{i j}
$$

Where $\mathrm{LIMB}_{i j}$ represents the profit at risk percentage for trade contractor $I$, in order to implement specific trade package $j ; \mathrm{P} @ \mathrm{R} \%$ ij represents Profit at Risk percentage for trade contractor $I$, to implement trade contractor $j$.

Since all non-owner parties carry the same responsibilities due to there are no meaning of contractor and sub-contractors, the relationship between contractors and other parties is at the same level of interfering. Therefore, the estimation for every party will be individually delivered as described in below figure 3 . 


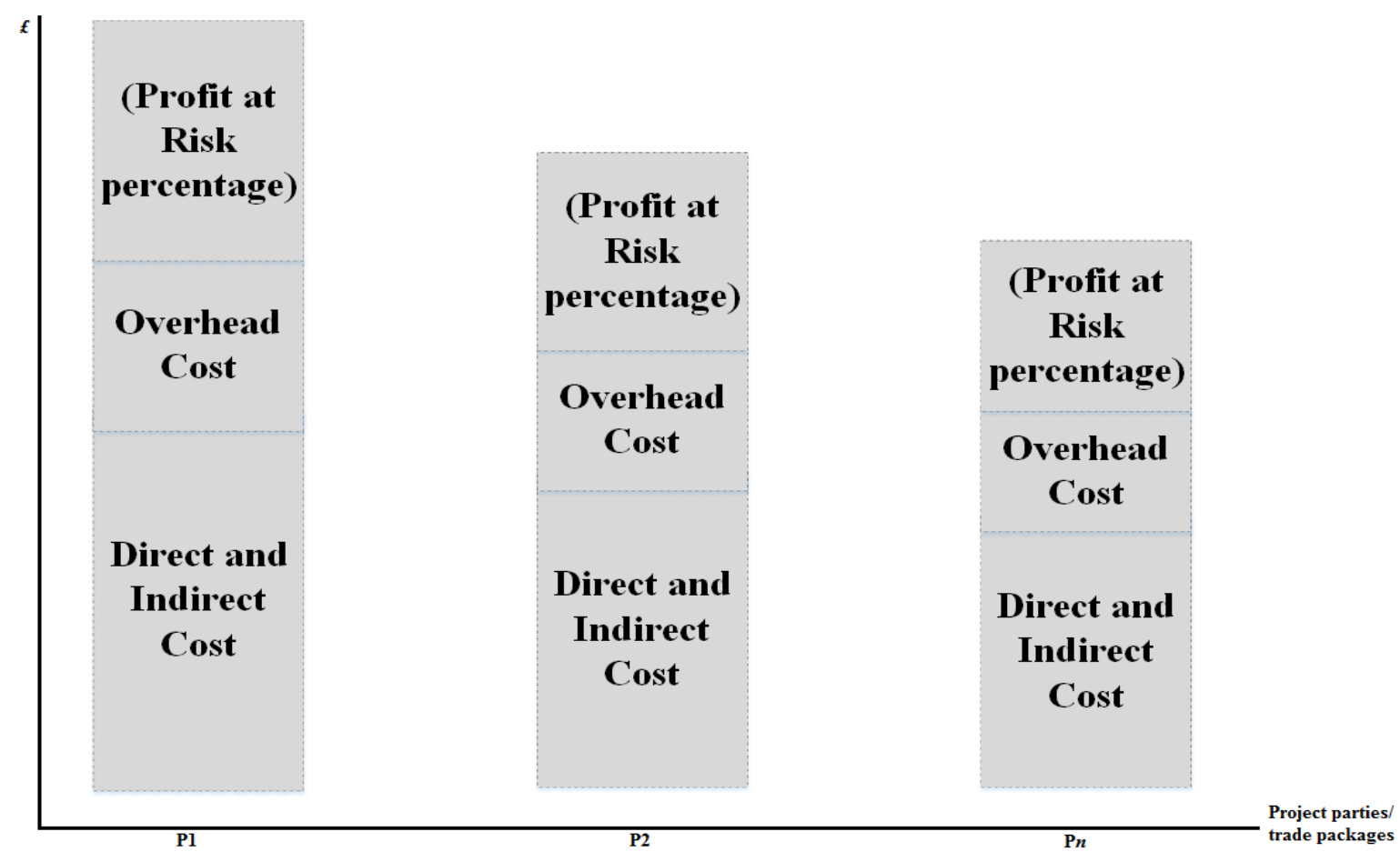

Figure 3. The structure of IPD cost estimation for each party

Formulation of cash-flow model:

The Cash-Out (CO) for trade contractor $i$ at specific period $p$, can be determined from the following model:

$$
C O_{i p}=\sum_{(i, p)} E C o A_{i j}(L I M B 2)_{O A}
$$

Where $\mathrm{ECoA}_{\mathrm{ij}}$ is Estimated Cost of Activities for trade package $J$, which will be executed by contractor $I$.

While the cost of each activity can be determined as follows:

$$
E C o A_{i j}=M C_{A P}+L C_{A P}+E q C_{A P}
$$

Where $\mathrm{MC}_{A P}$ is the Material Cost for Activity A, when needed for period $\mathrm{P}, \mathrm{LC}_{A P}$ is the Labour Cost for Activity A, when needed for period $\mathrm{P}, \mathrm{EqC}_{A P}$ is the Equipment Cost for Activity A when needed for period $\mathrm{P}$.

After determining the required resources for each activity, the ABC sheet will be filled by all cost data. Since ABC sheet is designed to include the activity cost, not resource costing, 
therefore, the inherent lack of integration between CBS and WBS has been sorted out in this method.

As aforementioned, the proposed Cash-In (CI) for trade contractor $i$ at specific period $p$, can be determined as follows:

$C I_{i p}=\sum_{(i, p)} E C o A_{i j}(L I M B 2)_{O A} \times(1+P @ R(L I M B 3) \%)$

Where P@R is Profit at Risk percentage:

$E P_{i j}=P @ R \% \times \sum_{(i, p)} E C o A_{i j}$

Where $\mathrm{EP}_{\mathrm{ij}}$ is Estimated Profit for trade contractor $I$, which will execute package $J$.

Since the contractors need indications regarding the expected maximum/minimum cash in during the execution stage, therefore, the following equations show the calculations of $\mathrm{EMnCI}_{i j}$ and $\mathrm{EMCI}_{i j}$

$$
\begin{aligned}
& E M n C I_{i j}=\sum_{(i, n)} E C o D A_{i j} \times(1+I R) I F I R \text { Monetary value }>L I M B 2 \& 3_{i j} \\
& E M C I_{i j}=\sum_{(i, n)} E C o A(L I M B 2)_{i j} \times(1+\text { Entire P@R }(L I M B 3) \%)
\end{aligned}
$$

Where EMnCI $\mathrm{I}_{\mathrm{ij}}$ is the Estimated Minimum Cash Inflow for trade contractor I, which will execute package $J$, and IR is the Increasing Rate. While $\mathrm{EMCI}_{\mathrm{ij}}$ is the Estimated Maximum Cash Inflow for trade contractor I, which will execute package $J$.

Therefore, the Maximum Overdraft for trade contractor I, which will execute package $J$, $\left(\mathrm{MO}_{\mathrm{ij}}\right)$ can be calculated using equation 10 . However, during the buyout stage, the estimator cannot determine the IR, therefore this overdraft represents the proposed percentage which will be lost, in case that the actual cost exceeds the LIMB 3 . In addition, the monetary value of $\mathrm{EMnCI}_{i j}$ should be more than the $\mathrm{EMCI}_{i j}$ as it is all cost with zero profit.

$$
M O_{i j}=E M C I_{i j}-E M n C I_{i j}
$$


The below figure 4, shows that at each milestone $n$, the above equations ( 1 and 2 ) should be implemented for each participant $i$. The continuous $\mathrm{S}$ curve represents LIMB 2, which involves direct, indirect, and overhead costs, and the periodic curve represents the LIMB2 plus profit at risk percentage. However, the below figure 4 assumes that the actual spent equals the planned, hence each cash-in instalment is located above cash-out curve. However, in other cases, such as the actual spent is more than planned and Budgeted Cost of Work Performed (BCWP); the movement of two curves will be completely different.

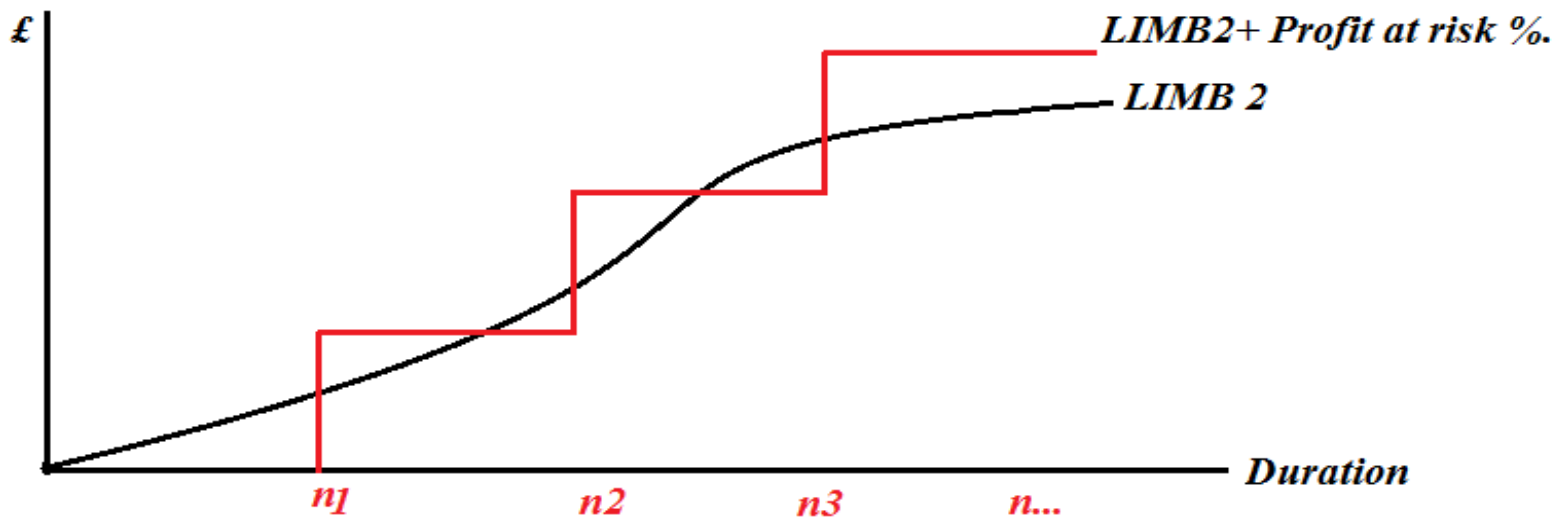

Figure 4. Proposed cash flow of IPD approach

\section{Different IPD cash flow scenarios}

Given that the payment under IPD approach relies on the achievement rate, there are different scenarios to address the relationship between cash in and cash out. The following scenarios show the most important cases that could take place while implementing IPD.

(1) Figure 5 - Case 1: Cost has been achieved in accordance with the planned value.

(2) Figure 5-Case 2: Expended cost is more than planned cost, which means that a part of profit at risk percentage has been used to cover the cost overrun issue.

(3) Figure 5-Case 3: Expended cost exceeded the LIMB 3, which comprises the entire cost, plus profit at risk percentage, the cash in and cash out relationship is completely 
different from traditional approach, So that, the client is responsible only to pay the direct cost to the contractor.
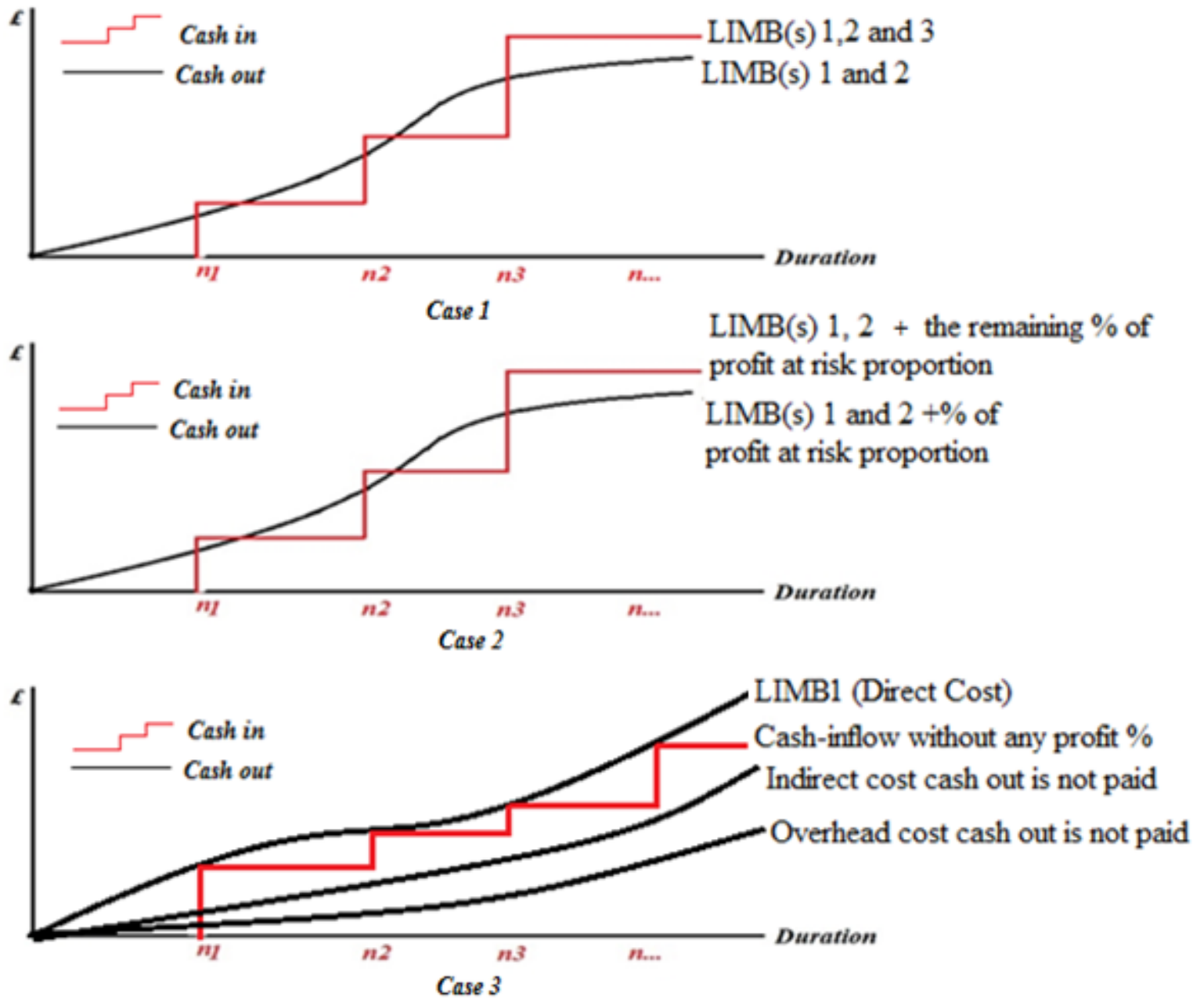

Figure 5. IPD Cash Flow Scenarios

\section{BIM-based cash flow}

Since BIM and IPD are interrelated processes to lean construction process, figure 6 shows the integration between schedule and cost within IPD approach using BIM capabilities. The model is divided into three steps, so that each step focuses on finishing the requirements of the following one until accomplishing the fully integrated cash flow for all participants. The developed model introduces a comprehensive solution for the fragmentation of WBS and CBS within $\mathrm{ABC}$, which deals with costs and schedule through a single hierarchy system. 


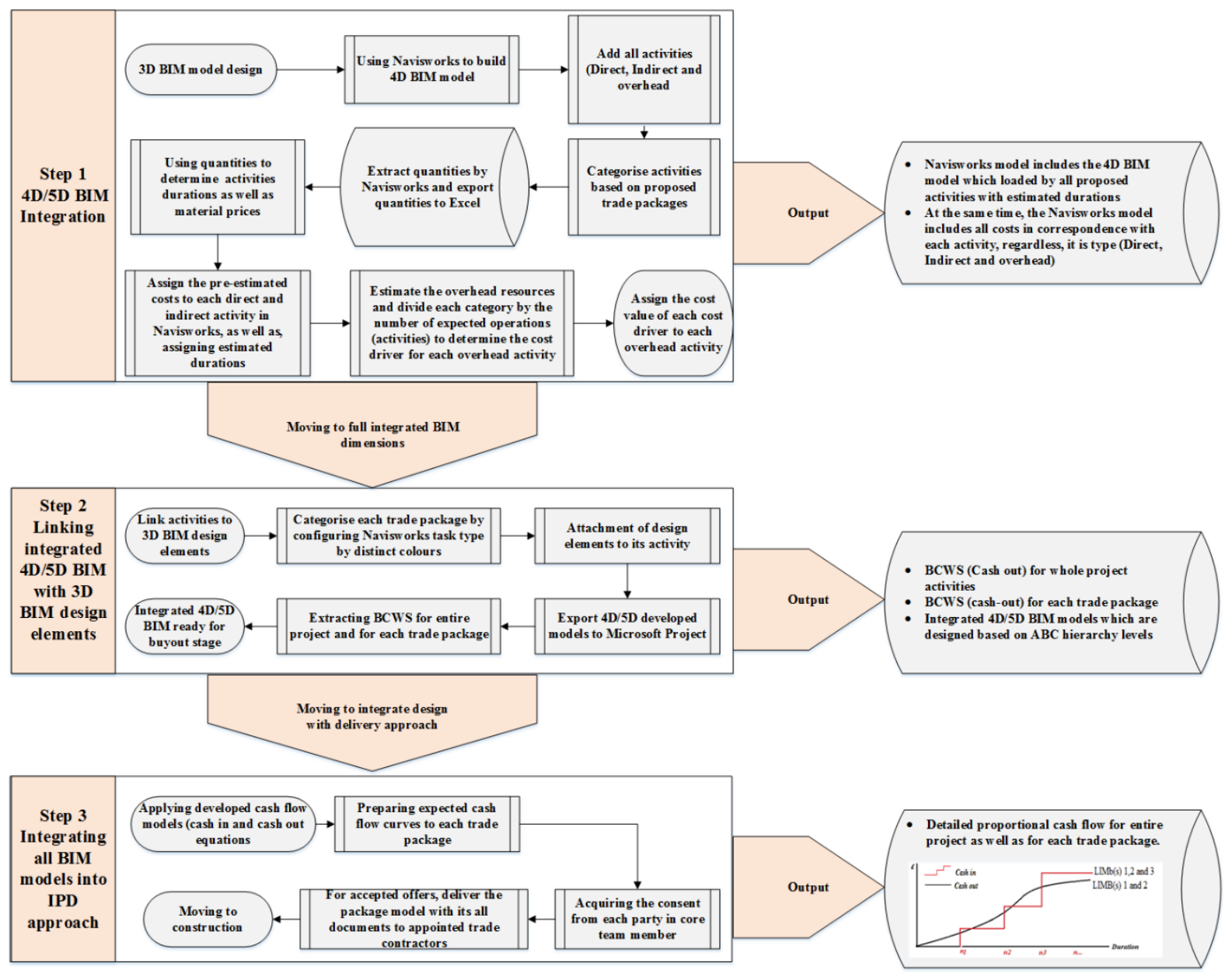

Figure 6. BIM and IPD Cash Flow Correlation

\section{Applicability of Developed Framework}

In order to validate the proposed framework, a real-life case study was conducted. The case study presents a set of 100 identical houses in which a property development company planned to build. The company decided to deliver the project using IPD and BIM. Since the tender stage is not applied in IPD approach, therefore, it is replaced by buyout stage, which relies on open pricing technique. Thereby, the cash flow analysis should be designed for this purpose, the estimated cash flow, especially cash-in should be presented as estimated maximum curve, which is the LIMB 3 limit and estimated minimum curve, which is the LIMB 1 limit. Since the literature review justified that BIM tools are necessary for successful delivery of projects within 
IPD approach, 4D/5D BIM data will be utilised in this case study. Figure 7 shows the five project packages.

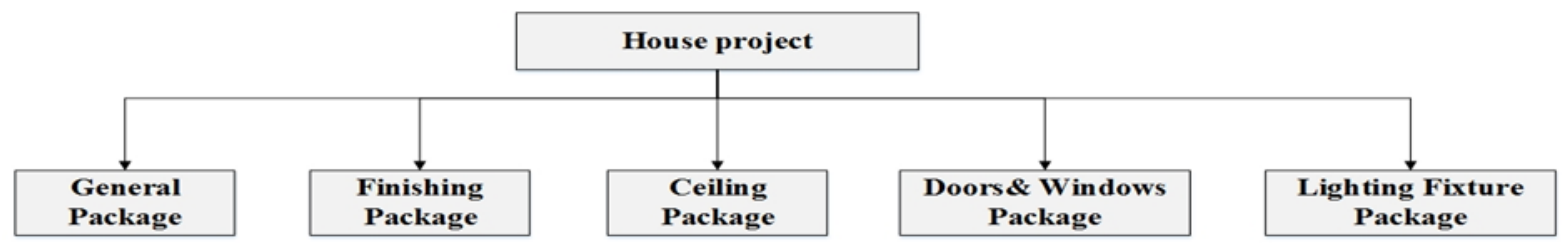

Figure 7. Project Packages

During documentation and buyout stage, the BIM team is responsible to develop 4D/5D BIM to prepare the project budget before emerging project parties' negotiation regarding profit at risk percentage and the decision in IPD approach is individual as the relationships are direct among all core team members. The compensation structure was agreed upon as follows: (1) the agreed profit at risk percentage was $20 \%$; (2) the saving cost allocation percentage for overhead project level cost was $70 \%$ for non-owner participants and $30 \%$ for owner, and for direct cost saving will be $50 \%$ for owner, and $50 \%$ for non-owner parties.

\section{Step 1: 4D/5D creation and integration}

As aforementioned, the 4D/5D BIM model should be developed at documentation stage. Figure 8 illustrates the project timeline, which was developed using BIM Navisworks platform, and to support the interoperability, a 5D BIM model was developed using the same platform. Figure 9 displays the allocation of project costs such as; material, labour, equipment, and subcontractor costs. As the $\mathrm{ABC}$ has been chosen to estimate project costs, the costs have been assigned to the project activities, and the developed timeline included overhead activities for each trade packages to ensure the cost structure of each package is properly estimated before emerging buyout stage. As stated in the literature review, the traditional cost estimation does not comply with IPD structure, as it relies on proportional overhead allocation, which could cause cost structure distortion and lead to misleading project pricing. 
'The Version of Record of this manuscript has been published and is available in international Journal of Construction Management (TJCM), Jan 2019, http://www.tandfonline.com/10.1080/15623599.2019.1573477'

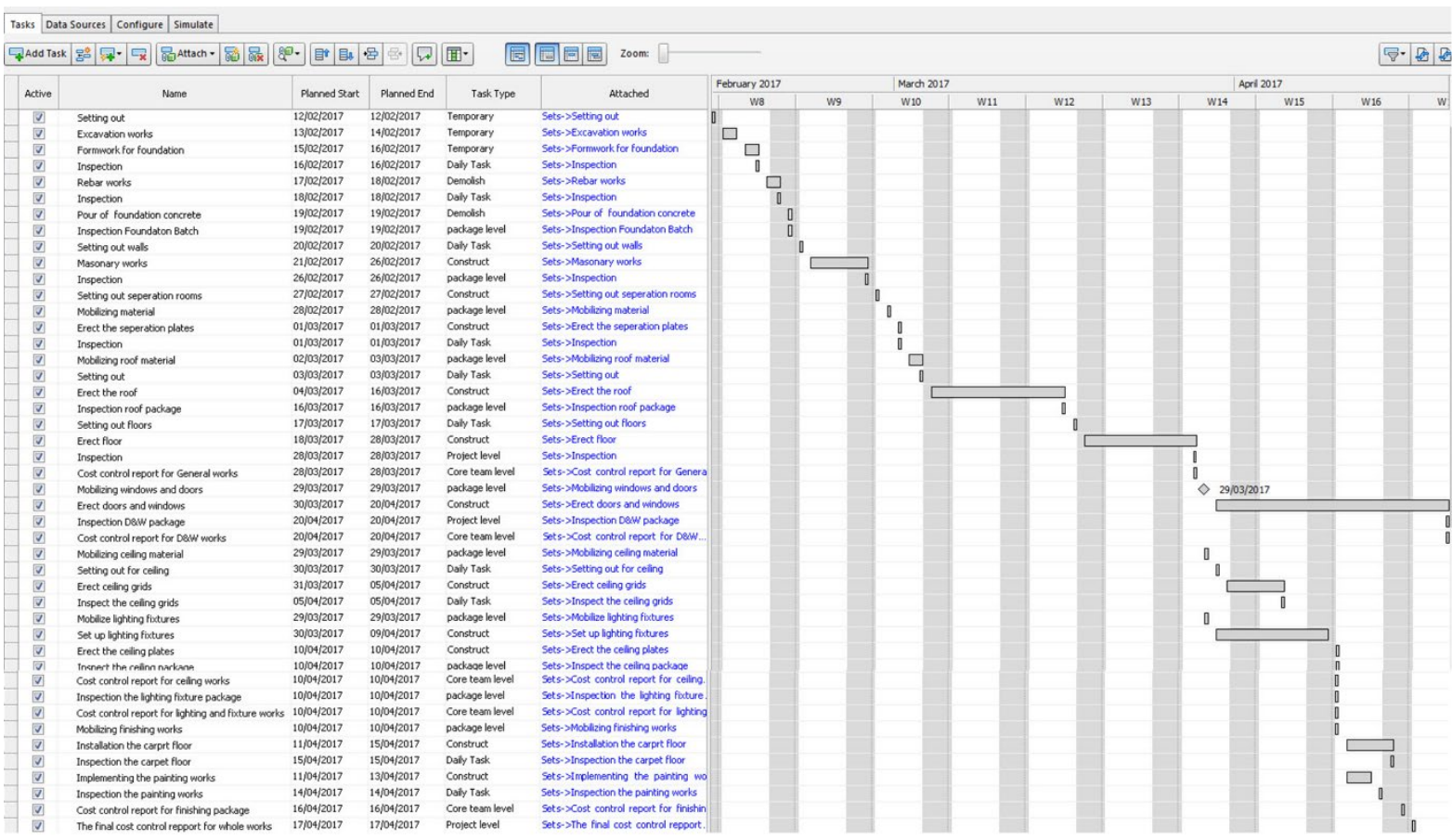

Figure 8. 4D BIM - Navisworks Platform

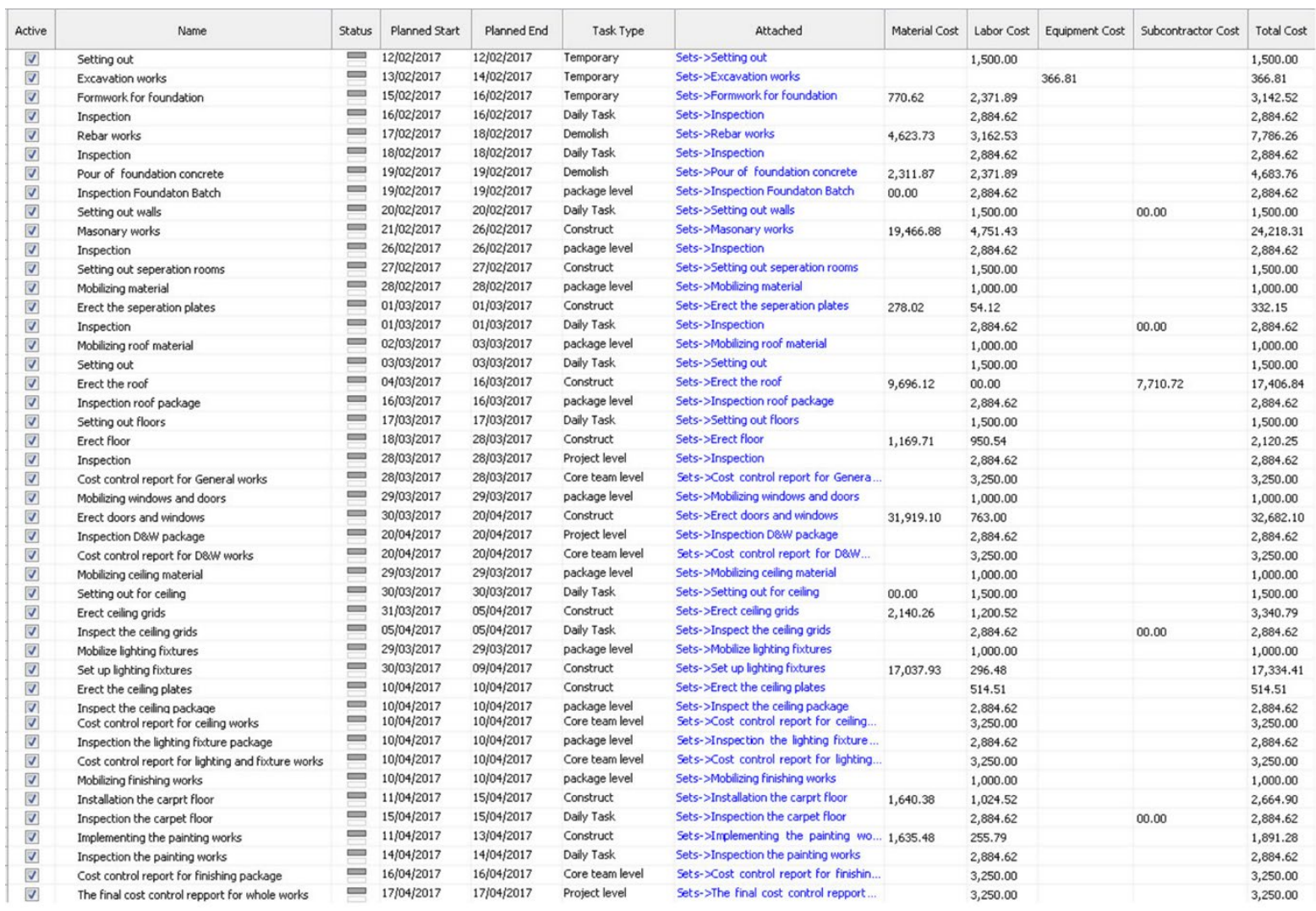

Figure 9. 5D BIM model - Navisworks Platform 
'The Version of Record of this manuscript has been published and is available in international Journal of Construction Management (TJCM), Jan 2019, http://www.tandfonline.com/10.1080/15623599.2019.1573477 '

\section{Step2: Development of cash flow}

After developing 4D/5D BIM models, in which its activities are linked with its design elements, the project budget should be developed at this stage. Notably, the budget should be developed separately for each trade package to enable negotiation at buyout stage. Table 1 shows the different packages along with their colour indices. Table 2 shows all values for each trade package as assigned to project timeline. By applying equation 1 and Table 2 illustrates the BCWS for LIMB 1, which is the direct cost which in IPD, it represents the minimum expected return in case of the actual cost exceeded the agreed profit at risk percentage. Likewise, it shows the BCWS of the overhead cost individually in case that there will be cost saving in the project, and IPD approach recommends sharing the achieved cost saving. The accumulative BCWS for all costs structure (i.e. direct, indirect and overhead costs) is computed based on equations 4 and 5 to estimate the maximum estimated cash in (Equation 9).

Table 2 illustrates the estimated maximum and minimum cash inflow for each trade package, therefore, the trade contractor should be able to identify the expected profit as well as the maximum overdraft that could happen during the project implementation. After applying equations 8 , and 9 with considering IR equals zero and using the agreed profit at risk percentage (20\%), the maximum cash in-flow for general package was $£ 106,817.7$, and the estimated minimum was $£ 57,224.8$. Hence the difference between those represents the profit at risk percentage plus the overhead cost, which was $£ 49,592.91$, and this only happens in case that the actual cost exceeded the planned LIMB 3. Without using ABC method, this kind of analysis to the cost structure could not be achieved, and the project parties will encounter the scarcity of cost index data. The estimated minimum and maximum cash inflow for all other packages are detailed in Table 2. 
'The Version of Record of this manuscript has been published and is available in international Journal of Construction Management (TJCM), Jan 2019, http://www.tandfonline.com/10.1080/15623599.2019.1573477 '

Table 1. Cost Packages

NO Package Colour index

1 General Package (GP)

2 Doors and Windows Package (DWP)

$3 \quad$ Ceiling Package (CP)

$4 \quad$ Lighting fixture Package (LP)

$5 \quad$ Finishing Package (FP) 
'The Version of Record of this manuscript has been published and is available in international Journal of Construction Management (TJCM), Jan 2019, http://www.tandfonline.com/10.1080/15623599.2019.1573477 '

Table 2. Estimated Cash Flow Distribution

\begin{tabular}{|c|c|c|c|c|c|c|c|c|c|c|c|}
\hline \multirow{2}{*}{ Package } & \multirow{2}{*}{ Cash flow parameters } & $£$ Feb & $£$ Feb & $£$ Feb & $£$ March & $£$ March & $£$ March & $£$ March & $£$ April & $£$ April & $£$ April \\
\hline & & W2 & W3 & W4 & W1 & W2 & W3 & W4 & W1 & $\mathrm{W} 2$ & W3 \\
\hline \multirow{7}{*}{ (GP) } & Accumulative BCWS & & & & $5,716.8$ & $5,716.8$ & $5,716.8$ & $5,716.8$ & $5,716.8$ & $16,509.2$ & $20,418.9$ \\
\hline & Accumulative BCWS & & & & & & & & & & \\
\hline & for overhead & & & & $5,384.6$ & $5,384.6$ & $5,384.6$ & $5,384.6$ & $5,384.6$ & $12,153.9$ & $15,530.6$ \\
\hline & Accumulative Direct & & & & & & & & & & \\
\hline & Cost & & & & 332.2 & 352.2 & 332.2 & 332.2 & 332.2 & 4,5כ5.4 & 4,888.5 \\
\hline & Maximum Cash inflow & & & & $6,860.1$ & $6,860.1$ & $6,860.1$ & $6,860.1$ & $6,860.1$ & $19,811.1$ & $24,502.7$ \\
\hline & Minimum Cash Inflow & & & & 332.2 & 332.2 & 332.2 & 332.2 & 332.2 & $4,355.4$ & $4,888.3$ \\
\hline \multirow{7}{*}{ (DWP) } & Accumulative BCWS & $1,866.8$ & 26,133 & $54,736.1$ & $63,038.4$ & $73,192.4$ & $79,875.7$ & $89,014.7$ & & & \\
\hline & Accumulative BCWS & & & & & & & & & & \\
\hline & for overhead & $1,500.0$ & דינו1 & נונ. & $11,030.0$ & נינסנת, & 25, & ט. & & & \\
\hline & Accumulative Direct & 3668 & 15070 & 01077 & 450000 & 536530 & 0526 & 248 & & & \\
\hline & Cost & & & & & & & & & & \\
\hline & Maximum Cash inflow & $2,240.2$ & 31,359 & $65,683.4$ & $75,646.1$ & $87,830.9$ & $95,850.8$ & 106,818 & & & \\
\hline & Minimum Cash inflow & 366.8 & 15,979 & $40,197.7$ & $45,999.9$ & $53,653.9$ & $55,952.6$ & $57,224.8$ & & & \\
\hline \multirow{3}{*}{$(\mathrm{CP})$} & Accumulative BCWS & & & & & & & $4,268.2$ & $15,706.9$ & $27,145.7$ & $40,661.7$ \\
\hline & Accumulative BCWS & & & & & & & 10000 & $1000 \Omega$ & ـ & 796 \\
\hline & for overhead & & & & & & & & 1000.0 & 1000.0 & .0 \\
\hline
\end{tabular}


'The Version of Record of this manuscript has been published and is available in international Journal of Construction Management (TJCM), Jan 2019, http://www.tandfonline.com/10.1080/15623599.2019.1573477'

\begin{tabular}{|c|c|c|c|c|c|}
\hline \multirow[t]{4}{*}{ 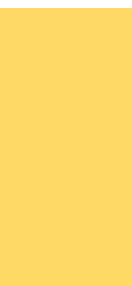 } & Accumulative Direct & \multirow[t]{2}{*}{$3,268.2$} & \multirow[t]{2}{*}{$14,706.9$} & \multirow[t]{2}{*}{$26,145.7$} & \multirow[t]{2}{*}{$32,682.1$} \\
\hline & Cost & & & & \\
\hline & Maximum Cash inflow & $5,121.9$ & $18,848.3$ & $32,574.8$ & $48,794.1$ \\
\hline & Minimum Cash inflow & $32,68.2$ & $14,706.9$ & $26,145.7$ & $32,682.1$ \\
\hline \multirow{6}{*}{ (LP) } & Accumulative BCWS & $3,056.8$ & $8,725.4$ & $15,475.3$ & $15,475.3$ \\
\hline & $\begin{array}{l}\text { Accumulative BCWS } \\
\text { for overhead }\end{array}$ & $2,500.0$ & $5,384.6$ & $11,620.0$ & $11,620.0$ \\
\hline & Accumulative Direct & 556.8 & $3,340.8$ & $3,855.3$ & $3,855.3$ \\
\hline & Cost & & & & \\
\hline & Maximum Cash inflow & $3,668.1$ & $10,470.5$ & $18,570.3$ & $18,570.3$ \\
\hline & Minimum Cash Inflow & 556.8 & $3,340.8$ & $3,855.3$ & $3,855.3$ \\
\hline \multirow{7}{*}{$(\mathrm{FP})$} & Accumulative BCWS & $4,466.9$ & $16,600.9$ & $24,917.5$ & $24,917.5$ \\
\hline & Accumulative BCWS & 1000.0 & 1000.0 & $7,583.1$ & $7,583.1$ \\
\hline & for overhead & & & & \\
\hline & Accumulative Direct & $3,466.9$ & $15,600.9$ & $17,334.4$ & $17,334.4$ \\
\hline & Cost & & & & \\
\hline & Maximum Cash inflow & $5,360.3$ & $19,921.1$ & $29,901.0$ & $29,901.0$ \\
\hline & Minimum Cash Inflow & $3,466.9$ & $15,600.9$ & $17,334.4$ & $17,334.4$ \\
\hline
\end{tabular}




\section{Result Analysis}

In buyout stage, the architect requires to show the completed budget plan to all project parties. As stated in the framework development section, the contractor will take the decision based on the expected maximum and minimum cash inflow. Figure 10 shows the estimated overdraft per package. That said, the overdraft implication is completely different from traditional delivery approaches, as the contractor, at the worst case, will be reimbursed the direct costs. In case that the actual values of project costs are located between the total cost and profit at risk values, this means the overdraft equals zero. In case of the actual project cost is located above LIMB 3, this means that overdraft equals the value of overhead costs, whether completely or partly. The way of presenting cash flow information warns contractors through minimising the project overhead by optimising the project schedule to implement more overhead activities at the same time, and accordingly minimise the number of cost drivers that will maximise the estimated minimum cash inflow. For instance, the overdraft in the finishing package, shown in Figure 10, is high due to the overhead costs are high. Using $\mathrm{ABC}$ enabled the estimators to precisely distinguish and identify the overhead costs to analyse the cost structure.

Since the IPD approach requires a trust environment throughout the project stages, the developed framework supports this by showing the maximum overdrafts could happen if the actual cost exceeded the profit at risk percentages (LIMB 3). Figure 10 shows the estimated overdraft values for each trade package and with integrating $\mathrm{ABC}$ into $4 \mathrm{D} / 5 \mathrm{D}$ BIM models, the overdraft is precisely determined using equation 10 . 


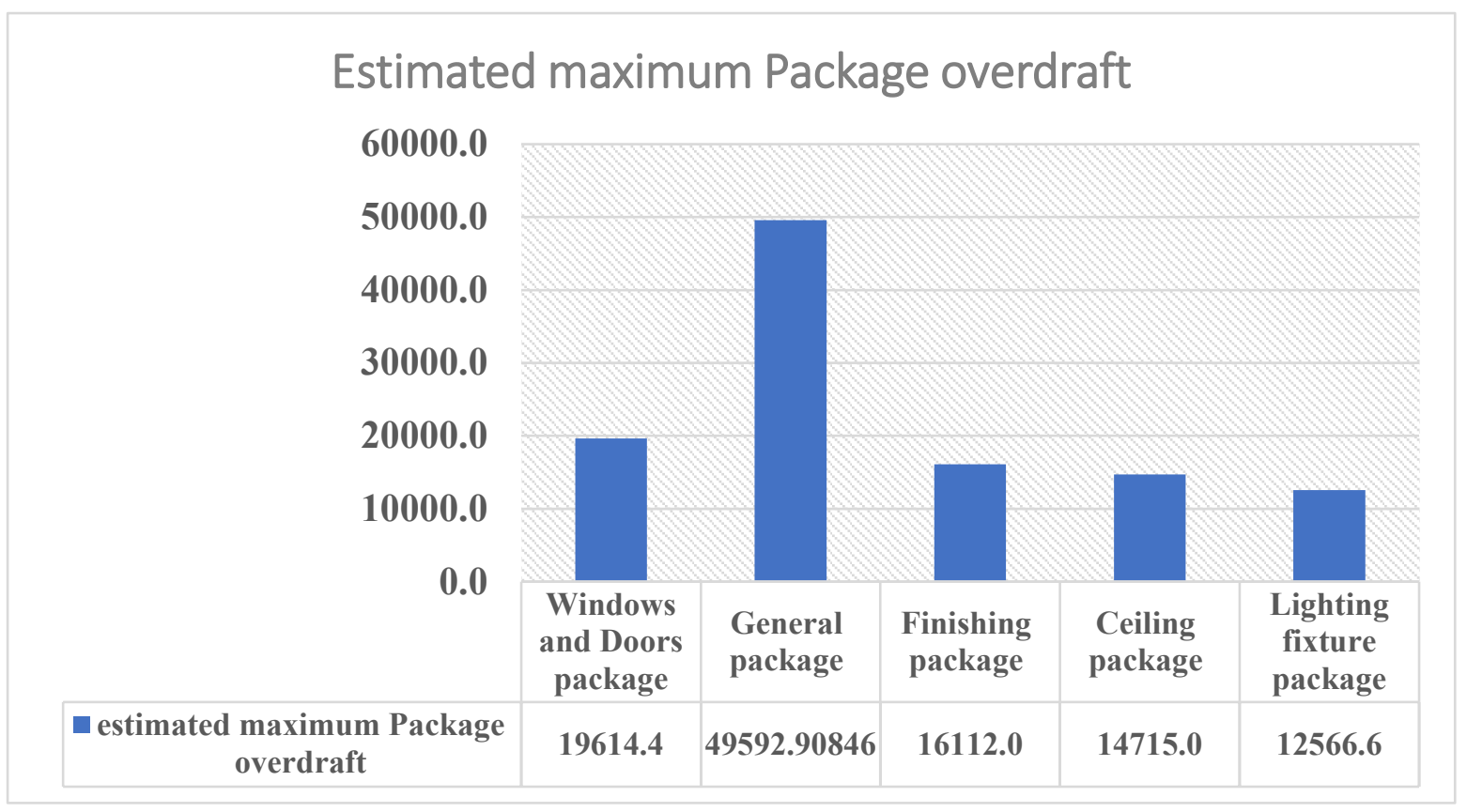

Figure 10. Estimated overdraft of each Package

Figure 11 illustrates that the maximum cash in deviations may occur in windows, doors, and packages by $80 \%, 80 \%$, and $79 \%$ respectively. This is due to the value of overhead costs which are high comparing to other packages such as finishing and lighting fixture packages by $33 \%$ and $42 \%$ respectively. Accordingly, the contractors will be completely aware regarding the maximum deviations which would happen in case of poor performance. In case that all displayed analysis will be presented during the IPD's buyout stage, this can ensure the successful project implementation since all the project parties are fully aware about all financial consequences. Even though these deviations were determined based on the planned direct and total cost, however these deviations indicate the expected gap if the trade contractor exceeds LIMB 3 limit. Figure 11 illustrates deviations of all packages, similarly, figure 12 illustrates the proposed cash flow plans for all packages, as well as estimated maximum required budget from the client, to be used for decision making during the buyout stage. Contrary to BIM based cash flow, which has been developed by Lu, Won and Cheng (2016), figure 12 illustrates the output of the proposed cash flow based BIM within the IPD approach. Accordingly, the 
'The Version of Record of this manuscript has been published and is available in international Journal of Construction Management (TJCM), Jan 2019, http://www.tandfonline.com/10.1080/15623599.2019.1573477 '

proposed cash flow chart shows the structure of cost estimation, and estimated minimum/maximum cash inflow, and enable project stakeholders to manage each package, which enables trade contractors to make the right decision.

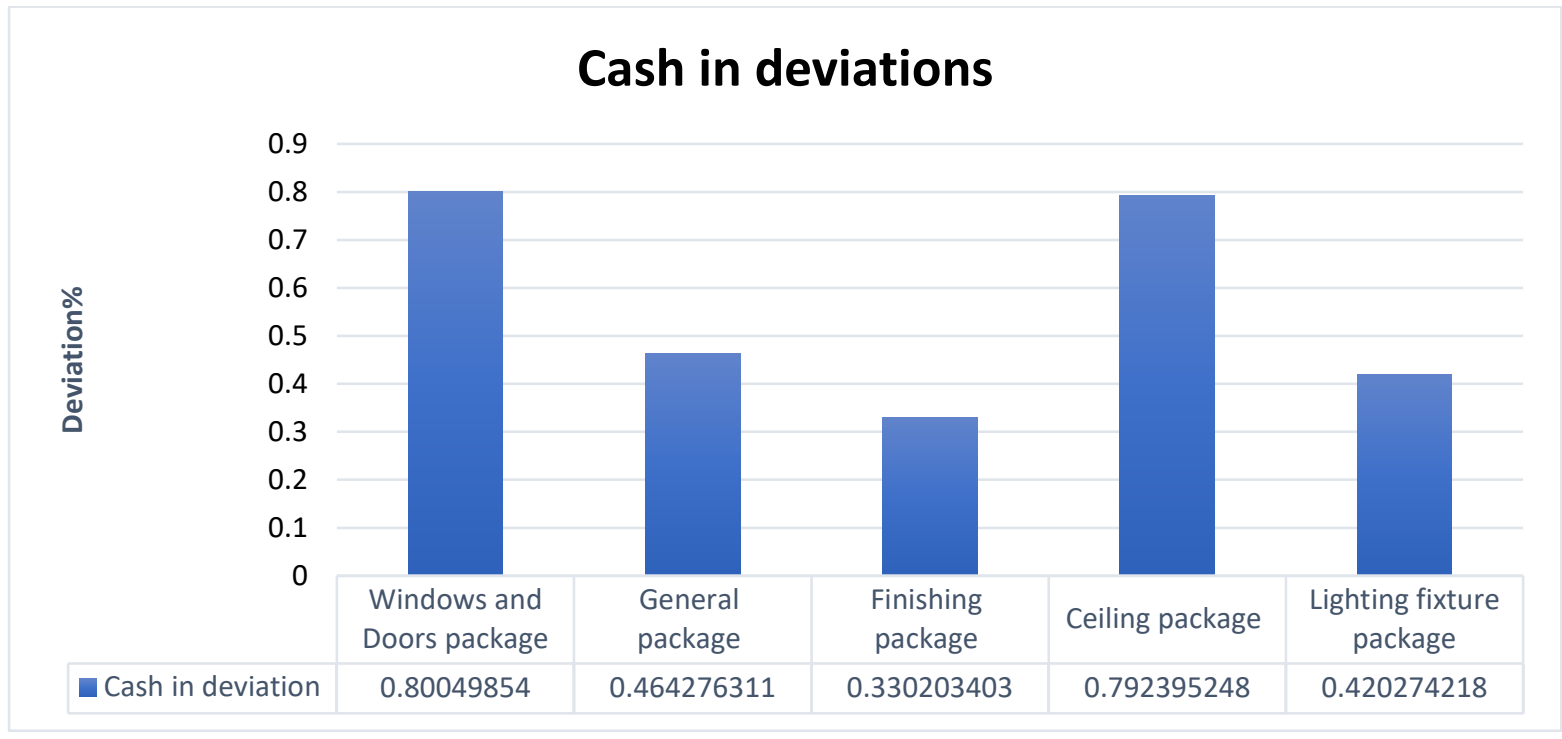

Figure 11. Packages cash in deviations' percentage

Figure 12 illustrates all cash flow data for all trade packages and the data is presented, whether using estimated maximum/minimum cash inflow, which include all cost elements (direct, indirect and overhead) are presented as S curve. Therefore, the contractors and client require to identify direct cost of the activities at the buyout stage, since the client is liable to pay the actual cost of direct activities, in case that the actual cost exceeds Limb 3. Therefore, the monetary value for minimum estimated cash inflow indicates the planned cost for direct activities and it enables project parties to track these activities during the execution stage, in order to determine the actual value. The deviation between estimated maximum/minimum cash inflow gives an indication to restructure the cost estimation in case overhead and indirect costs are larger than direct cost. Without using $\mathrm{ABC}$, the filtering of direct, indirect, and overhead activities could not be attainable, therefore, the developed cash flow will not be reliable and representable to the nature of the project. The embedded data in figure 12 should be displayed on the IPD's big room to enable all participants to manage their cash flow, particularly the 
'The Version of Record of this manuscript has been published and is available in international Journal of Construction Management (TJCM), Jan 2019, http://www.tandfonline.com/10.1080/15623599.2019.1573477 '

costs is only reimbursed, and profits will be shared after all works will be accomplished by all

participants.

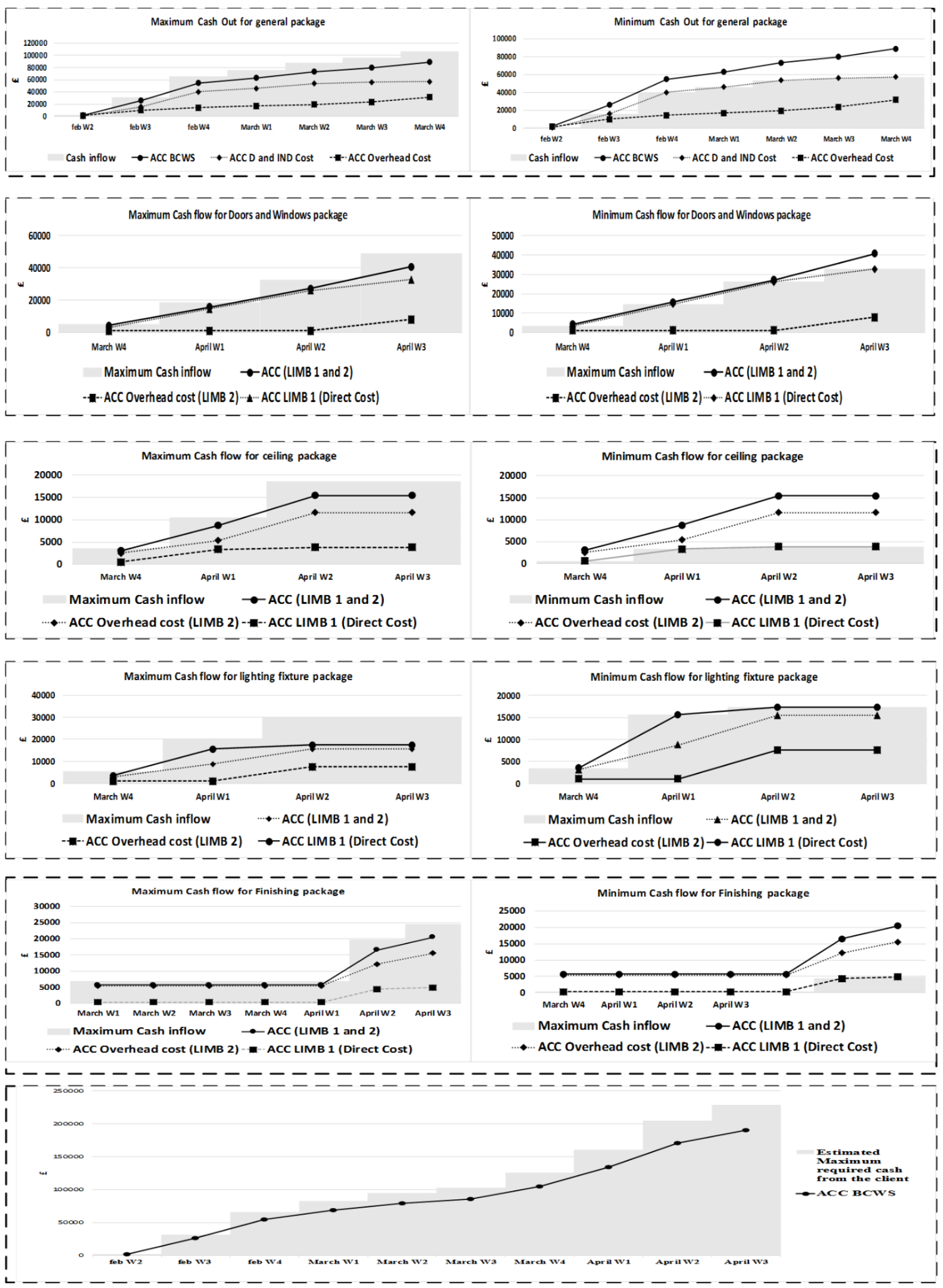

Figure 12 . Project Cash Flow Plans 
'The Version of Record of this manuscript has been published and is available in international Journal of Construction Management (TJCM), Jan 2019, http://www.tandfonline.com/10.1080/15623599.2019.1573477 '

\section{Conclusion and Future Research}

This paper presented a cash flow methodology framework to maximise the value of integrating 4D/5D BIM in generating the project cash flow within the IPD approach. The developed framework includes three steps to integrate 4D/5D BIM as follows: 1. Integration of cost and schedule data to solve the endemic problem of integrating WBC and CBS. This research adopted $\mathrm{ABC}$ for cost estimation, since the costs are assigned to activities, and not resources; 2. Linking cost/schedule data to BIM elements for grouping and sorting the project packages and the IPD's buyout stage, which requires a separate cash flow plan for each package; and 3. Providing project parties with all required financial data for informed decision making, such as providing contractors with the estimated maximum/minimum cash inflow, and giving indications to trade contractors for all possible overdrafts that might occur during project execution stage.

The case study highlights that integrating 4D/5D BIM, using ABC costing method, assures that all costs have been assigned precisely to all activities. Overhead resources are presented as activities, to enable determining the right proportional of overhead consumption for each trade package. This process leads to a reliable IPD cost profile structure to all project participants and enables contractor in taking timely/informed decisions at the buyout stage. Moreover, the case study results showed that the 4D/5D BIM integration, using $\mathrm{ABC}$, gives the contractor the opportunity to minimise the gap between the estimated minimum/maximum cash inflow by minimising the overhead costs, and in case that the actual cost exceeded the limb3, the owner will be liable to pay the direct cost only, such as finishing package.

In practical terms, findings will be invaluable for IPD users, given the simplicity and userfriendliness of proposed models. All the tasks are aligned with the implementation stages, and easily expressed to allow IPD users to predict all possible financial consequences during the 
'The Version of Record of this manuscript has been published and is available in international Journal of Construction Management (TJCM), Jan 2019, http://www.tandfonline.com/10.1080/15623599.2019.1573477 '

project execution stage. Furthermore, the presented methodology framework prevents IPD cost distortion by distinguishing between all overhead costs and the agreed profit percentage.

This research is a part of an automated cost management system within IPD approach, using BIM tools, therefore, further research is in progress for building an automated cost control system within IPD using Earned Value Management (EVM). Due to using a small case study for validation, the deviations between minimum and maximum cash inflow seem to be large since the list of direct activities is short, which cause this significant deviation, however, the methodology remains valid regardless the amount of deviations. Therefore, the research requires further validation using a large-scale case study, which was executed using IPD, in order to measure its validity in a large scale sector.

\section{References}

Andalib R, Hoseini A, Gatmiri B. 2018. A stochastic model of cash flow forecasting considering delays in owners' payments. Construction Management and Economics, 36(10), pp.545-564.

Ashcraft H. 2009. The IPD Framework. San Francisco, CA 94105: Hanson Bridgett LLP.

Ashcraft H. W. 2008. Building information modeling: A framework for collaboration. Constr. Lawyer, 28 3, 1-14.

Batselier J, Vanhoucke M. 2017. Improving project forecast accuracy by integrating earned value management with exponential smoothing and reference class forecasting. International Journal of Project Management, 35(1), pp.28-43.

Baumeister R. F and Leary M. R. 1997. Writing narrative literature reviews. Review of General Psychology, 3, 311-320

Bedrick J, Rinella T. 2006. A report on integrated project delivery, American Institute of Architects, Washington, D.C.

Bem D. J. 1995. Writing a review article for Psychological Bulletin. Psychological Bulletin, 118, 172177

Bryman A. 2001. Social research methods. Oxford: Oxford University Press.

Callahan J. T. 1998. Managing transit construction contract claims, Transportation Research Board, Transportation cooperative research program synthesis 28, National Academy Press, Washington, D.C., 1-59.

Carbonara N, Pellegrino R. 2018. Revenue guarantee in public-private partnerships: a win-win model. Construction Management and Economics, 36(10), pp.584-598.

Chiang B. 2013. INDIRECT LABOR COSTS AND IMPLICATIONS FOR OVERHEAD ALLOCATION. ACCOUNTING \& TAXATION, 5(1).

Chou J.-S. 2011. Cost simulation in an item-based project involving construction engineering and management. International Journal of Project Management, Vol. 29 No. 6, pp. 706-717.

Clark P, Hill N.T, Stevens K. 2002. Activity based costing in Ireland: Barriers and opportunities for change. Critical Perspectives on Accounting, No. 1, pp. 443-468.

Cooper H. 2003. Editorial. Psychological Bulletin, 129, 3-9. 
'The Version of Record of this manuscript has been published and is available in international Journal of Construction Management (TJCM), Jan 2019, http://www.tandfonline.com/10.1080/15623599.2019.1573477 '

Cui Q, Hastak M, Halpin, D. 2010. Systems analysis of project cash flow management strategies. Constr. Manag. Econ. 28 (4), 361-376.

Dandago K. I. Tijjani B. 2005. Cost and Management Accounting, Gidan-DabinoPublishers, KanoNigeria.

Das T, Teng, B. 2001. A risk perception model of alliance structuring. Journal Of International Management, 7(1), 1-29. doi: 10.1016/s1075-4253(00)00037-5

DeBernard D. M. 2008. Beyond collaboration-The benefits of integrated project delivery. AIA Soloso website, 〈http://soloso.aia.org/eKnowledge/Resources/Documents/AIAP037286〉 (Oct. 28, 2009).

Delerue H, Simon E. 2009. National Cultural Values and the Perceived Relational Risks in Biotechnology Alliance Relationships. International Business Review, 18, 14-25. http://dx.doi.org/10.1016/j.ibusrev.2008.11.003

Eastman C, Liston K, Sacks R, Teicholz, P. 2011. A BIM Handbook: A Guide to Building Information Modeling for Owners, Managers, Designers, Engineers and Contractors. 2nd ed., Wiley, NY.

El Asmar M, Hanna A. S, Loh, W. Y. 2013. Quantifying Performance for the Integrated Project Delivery System as Compared to Established Delivery Systems. Journal of Construction Engineering and Management, 139(11). http://dx.doi.org/10.1061/ (asce) co.19437862.0000744

Elazouni A. 2009. Heuristic method for multi-project finance-based scheduling. Constr. Manag. Econ. 27 (2), 199-211.

Fan S, Wu C, Hun C. 2015. Integration of Cost and Schedule Using BIM. Journal of Applied Science and Engineering, [online] 18(3), pp.223-232. Available at: http://www2.tku.edu.tw/ tkjse/183/02-CE10310_1368.pdf [Accessed 29 Jul. 2018].

Fang Y, Ng S. 2011. Applying activity-based costing approach for construction logistics cost analysis. Construction Innovation, 11(3), pp.259-281.

Hastak M. 2015. Skills \& knowledge of cost engineering. Morgantown, W.V.: AACE International.

Holland N, Hobson D. 1999. Indirect cost categorization and allocation by construction contractors. Journal of Architectural Engineering, ASCE, 5(2) 49-56.

Jung Y, Woo S. 2004. Flexible Work Breakdown Structure for Integrated Cost and Schedule Control, J. Constr. Eng. Manage., Vol. 130, No. 5 . doi: 10.1061/(ASCE)0733-9364(2004)130:5 (616).

Kaka A.P, Price A. 1991. Net cash flow models: are they reliable? Constr. Manag. Econ. 9 (3), 291308.

Kang L, Paulson B. 1998. Information Management to Integrate Cost and Schedule for Civil Engineering Projects. Journal of Construction Engineering and Management, 124(5), pp.381389.

Kent D, Becerik-Gerber B. 2010. Understanding Construction Industry Experience and Attitudes toward Integrated Project Delivery. Journal of Construction Engineering and Management, 136(8), pp.815-825.

Kim H, Grobler F. 2013. Preparing a construction cash flow analysis using Building Information Modeling (BIM) technology. KICEM J. Constr. Eng. Project Manag. 1-9.

Kim J. 1989. An Object-Oriented Database Management System Approach to Improve Construction Project Planning and Control (PhD thesis) University of Illinois, Urbana, Ill.

Kim T, Kim Y. 2016. ACTIVITY-BASED COSTING FOR PROCESS IMPROVEMENTS.

Kim Y, Ballard G. 2001. Activity-Based Costing and its Application to Lean Construction. Proceedings of the 9th Annual Conference of the International Group for Lean Construction, Singapore.

Kishore V, Abraham D.M, Sinfield J.V. 2011. Portfolio cash assessment using fuzzy systems theory. J. Constr. Eng. Manag. 137 (5), 333-343.

Lawrence M, Pottinger R, Staub-French S, Nepal M.P. 2014. Creating flexible mappings between Building Information Models and cost information. Automation in Construction, 45, 107-18. doi: http://dx.doi.org/10.1016/j.autcon.2014.05.006

Lee D.-E, Lim T.-K, Arditi D. 2011. Stochastic project financing analysis system for construction. J. Constr. Eng. Manag. 138 (3), 376-389. 
'The Version of Record of this manuscript has been published and is available in international Journal of Construction Management (TJCM), Jan 2019, http://www.tandfonline.com/10.1080/15623599.2019.1573477 '

Love P, Davis P, Chevis R., Edwards D. 2011. Risk/Reward Compensation Model for Civil Engineering Infrastructure Alliance Projects. Journal Of Construction Engineering And Management, 137(2), 127-136. doi: 10.1061/(asce)co.1943-7862.0000263

Lu Q, Won J, Cheng J. 2016. A financial decision making framework for construction projects based on 5D Building Information Modeling (BIM). International Journal of Project Management, 34(1), pp.3-21.

Miller J. A. 1996. Implementing activity-based management in daily operations, John Wiley \& Sons, New York, NY

Moder J, Phillips C, Davis E. 1995. Project management with CPM, PERT, and precedence diagramming. Middleton, Wis.: Blitz Pub. Co.

Montaser A, Moselhi O. 2015. METHODOLOGY FOR AUTOMATED GENERATION OF 4D BIM. In 5th International/11 th Construction Specialty Conference.

Rasdorf W, Abudayyeh O. 1991. Cost- and Schedule-Control Integration: Issues and Needs. Journal of Construction Engineering and Management, 117(3), pp.486-502.

Ross J. 2003. Introduction to project alliancing (On Engineering and Construction Projects).

The American Institute of Architects. 2007. Integrated Project Delivery: A Guide. Version 1. [online] AlA California Council and AIA National. Available at: https://info.aia.org/SiteObjects/files/IPD_Guide_2007.pdf [Accessed 29 Jul. 2018].

Tsai W, Yang C, Chang J, Lee H. 2014. An Activity-Based Costing decision model for life cycle assessment in green building projects. European Journal of Operational Research, 238(2), pp.607-619.

Wang P, Du F, Lei D, Lin T. W. 2010. The choice of cost drivers in activity-based costing: Application at a Chinese oil well cementing company. International Journal of Management, 27(2), pp. 367-373.

Yuan Fang S, Thomas Ng. 2011. Applying activity-based costing approach for construction logistics cost analysis. Construction Innovation, Vol. 11 Issue: 3, pp.259-281, https://doi.org/10.1108/14714171111149007. 